\title{
Theoretical Investigation of Thermal Expansion Coefficients of SiC Reinforced Copper Matrix Composites ${ }^{\dagger}$
}

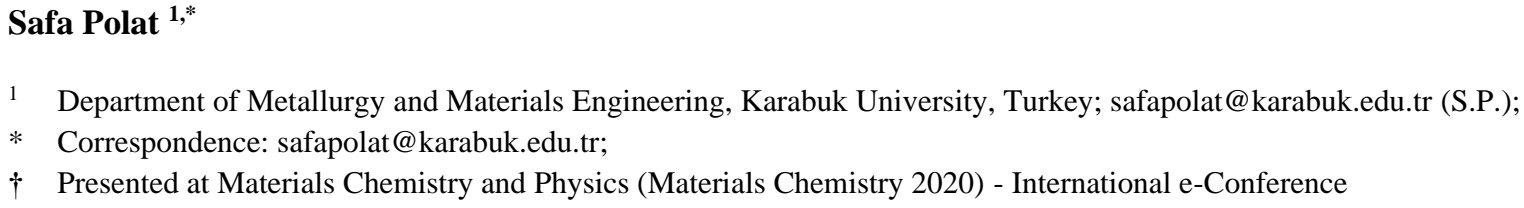

1 Department of Metallurgy and Materials Engineering, Karabuk University, Turkey; safapolat@karabuk.edu.tr (S.P.);

* Correspondence: safapolat@karabuk.edu.tr;

$\dagger$ Presented at Materials Chemistry and Physics (Materials Chemistry 2020) - International e-Conference

Received: 16.09.2020; Revised: 20.09.2020; Accepted: 24.09.2020; Published: 27.09.2020

\begin{abstract}
The thermal expansion coefficient (CTE) of the copper element, which is widely used in the electronics industry, is quite high. It is of great importance to decrease the CTE value in order not to deform against the heat it is exposed to. In this study, it is aimed to theoretically examine the changes in CTE value when $\mathrm{SiC}$ supplement is applied to pure copper. For this purpose, CTE value calculations were made according to Kerner and Turner's models for composites that were reinforced at different rates by volume. Sample studies in the literature have been utilized for percent component ratios. In this context, the amount of reinforcement was adjusted to be 5, 10,15, and 20vol.\% by volume. According to the findings, it was observed that there was \%4-17 decrease in CTE value based on the Kerner model and \% 7-26 decrease based on the Turner model.
\end{abstract}

Keywords: coefficient of thermal expansion; silicone carbid; cooper; Kerner model; Turner model.

(C) 2020 by the authors. This article is an open-access article distributed under the terms and conditions of the Creative Commons Attribution (CC BY) license (https://creativecommons.org/licenses/by/4.0/).

\section{Funding}

This research received no external funding.

\section{Acknowledgments}

I would like to thank Karabuk University's Materials Research Center.

\section{Conflicts of Interest}

The authors declare no conflict of interest. 